\title{
Europeans claim industry handouts are not a problem
}

$\mathrm{A}$ lthough warm-climate holiday junkets thinly disguised as medical conferences are not uncommon for doctors in Europe, the pharmaceutical industry is nowhere near as aggressive overseas in seeking to influence the therapeutic decisions of physicians by way of handouts, European administrators say.

Like their Canadian counterparts, the administrators also say that Big Pharma has less of an invasive influence on medical education in Europe than in the
United States (US). Canadian medical school officials argue that low levels of abuse mitigate the need for more restrictive policies on pharmaceutical and medical devices industry handouts for medical education (CMAJ 2008;179[3]: 225-6), similar to those recently adopted by the Association of American Medical Colleges (CMAJ 2008:178[13]:1651-2).

The European administrators suggested that the scale of pharmaceutical industry handouts is a function of the level of drug spending within a nation.

\section{Industry handouts to be re-examined}

$\mathrm{C}$ anadian medical school administrators may be inching toward the development of some form of guidelines governing pharmaceutical and medical devices industry handouts for undergraduate, postgraduate and continuing medical education.

The Association of Faculties of Medicine of Canada and the medical education advocacy group, the Canadian Association for Medical Education, will meet with representatives of the Association of American Medical Colleges, which recently adopted restrictive guidelines on industry handouts (CMAJ 2008;178[13]:1651-2), with an eye toward developing some form of Canadian "position paper" on the issue by the spring of 2009.

There's no question that the United States (US) move towards limitations on accepting goodies and cash from industry has provided "some impetus" to re-examine the issue in Canada, says Dr. Michael

Allen, one of 3 members on a recently appointed Canadian Association for Medical Education working group that has been struck to examine the issue.

"But we're very early in the game and it's way too early to say whether" what might ultimately emerge are strict guidelines similar to those adopted in the US, Allen says. The 2 Cana-

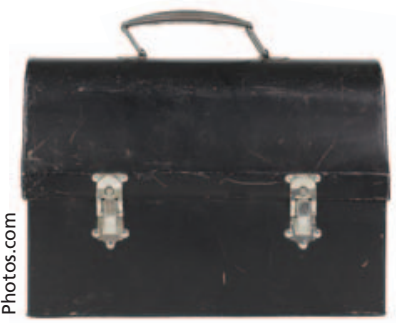
dian associations will meet with the Association of American Medical Colleges in November 2008 to discuss the handouts issue before deciding their next course of action. Allen says the Canadian bodies must also determine whether there is an appetite within the country for more restrictive policy governing interaction between industry and physicians or students.

Meanwhile, the US state of Massachusetts moved to restrict drug industry gifts to physicians or other health care professionals by passing legislation that will prohibit drug company representatives from dishing out some types of handouts, like sports tickets, while requiring that all gifts valued at more than US\$50 be publicly disclosed. Among cash payments that will have to be disclosed on the public database are direct payments to physicians for participation in speaker's bureaus. But third-party payments to institutions for continuing medical education will be exempt from the reporting requirement.

The legislation also requires the Massachusetts Department of Public Health to enact a regulatory code of conduct for industry representatives like drug salesmen, with violations to be punishable by a US\$5000 fine. - Wayne Kondro, CMAJ

United Kingdom (UK) spending on drugs is less than that of the US, where Big Pharma is focusing its efforts, says Des Spence, spokesperson for the UK branch of No Free Lunch, a New Yorkbased not-for-profit organization that advocates for "non-promotion-based medicine."

Still, the move to adopt a zerotolerance approach to pharmaceutical companies funding events at medical schools and teaching hospitals in the US is very important for the UK, Spence says.

"The involvement of any pharmaceutical company on campus is inappropriate," Spence says. "Students take a lead from academics, who set the standard. It is probably less of an issue in the UK than in the US, but nonetheless it is important to draw a line in the sand about what is and is not acceptable."

Barring the adoption of more restrictive policies, individual European nations will continue to be regulated in somewhat haphazard fashion. There are no policies in some nations, while others are regulated by a nation-specific or Europe-wide directives.

In the UK, for example, there is no guidance for medical schools about drug company funded seminars, says Katy Petty-Saphon, executive director of the UK Council of Heads of Medical Schools.

Faculty can be invited to speak at conferences in their area of expertise, or be asked to put their name as a lead author to a drug-company funded research paper. Industry-funded events in schools are nonexistent.

In teaching hospitals, however, drug company-funded lunchtime meetings (with free sandwiches) are common.

Insofar as there are guidelines governing handouts directly to physicians, there appear to be a mixture of professional association guidelines and industry codes of conduct, all with varying degrees of specificity.

A European Commission Directive (www.emea.europa.eu/pdfs/human/pmf /2001-83-EC.pdf) states that hospitality can only be offered to doctors, directly or indirectly, at events for "purely professional and scientific purposes." 


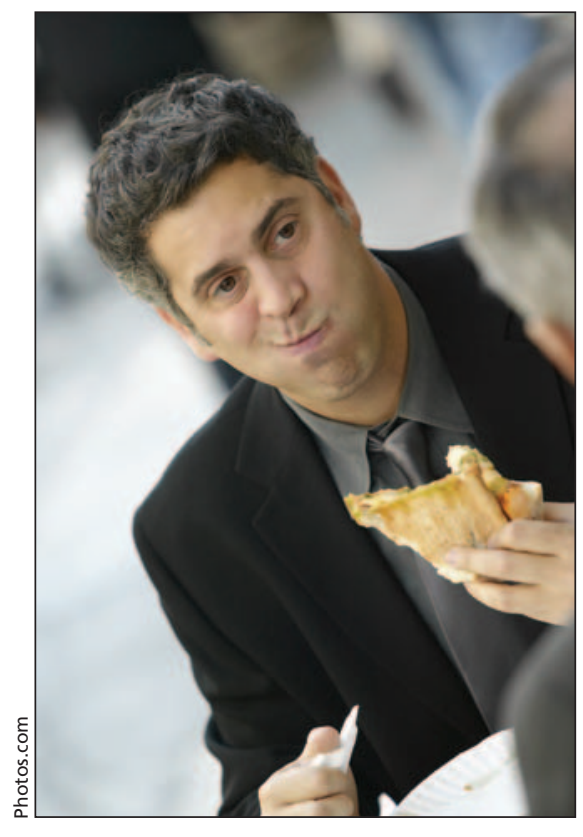

Self-regulation, and little in the way of censure, appears the norm in European handling of industry handouts to physicians.

As well, "no gifts, pecuniary advantages or benefits in kind may be supplied, offered or promised to such persons unless they are inexpensive and relevant to the practice of medicine or pharmacy."

The European Federation of Pharmaceutical Industries and Associations' code (www-efpia.eu/content/Default .asp@PageID=366) says that events should be held within the home nation of a firm "unless most of the invitees are from outside of its home country and it makes greater logistical sense to hold the event in another country. Hospitality must not include sponsoring or organising entertainment (e.g., sporting or leisure) events. Gifts for the personal benefit of healthcare professionals (such as tickets to entertainment events) should not be offered or provided."

Separate national codes of contacts covering each member's country are available at www.efpia.eu.

Most medical associations have some measure of code of practice, typically placing the onus on doctors to resist the temptation of accepting goodies.

The UK's General Medical Council, for example, (www.gmc-uk.org /guidance/good_medical_practice/index .asp), advises that doctors "must not ask for or accept any inducement, gift or hospitality which may affect or be seen to affect the way they prescribe."

The German Medical Association, meanwhile, says that industry sponsorship of continuing education events must be free of commercial interests and transparent, while speakers must disclose connections with industry (www.bundesaerztekammer.de).

Self-regulation appears the norm. The UK's Prescription Medicines Code of Practice Authority, for example, publishes regular reports on complaints that it investigates into whether its code of practice has been breached.

For instance, it recently ruled that the medical director of Teva UK Ltd breached a provision against using educational meetings for promotional purposes.

That finding was published but there was no other censure, although it is within the Authority's purview to suspend firms from the Association of the British Pharmaceutical Industries. Lynn Eaton, London, England

DOI:10.1503/cmaj.081268

\section{Complaints rise but}

\section{legal actions decline}

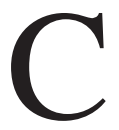

anadian doctors are now far less likely to be named in legal actions, but more likely to face complaints lodged with their provincial regulatory colleges, compared to 10 years ago, according to the Canadian Medical Protective Association.

The association, a nonprofit medical defense fund that represents the vast majority of Canadian doctors, says the chances of a member doctor being named in a lawsuit are about half what they were a decade ago. (The tally was 928 for legal actions commenced in 2007 , according to the association's annual report.)

On the other hand, since 1998 there has been a more than $30 \%$ increase in legal and other assistance provided to physicians facing college complaints. In 2007, the association had some degree of involvement, nationwide, in
2784 regulatory college matters, according to the report.

In Ontario alone, the number of complaints climbed to 4738 in 2007 from 3844 just 2 years earlier, according to the College of Physicians and Surgeons of Ontario.

The reason for the lower trend in lawsuits is not clear, but the association speculates it may be linked to improved medical care and risk management, as well as a better understanding of patient safety.

Meanwhile, the increase in complaints about doctors is probably due to greater public awareness about the role of regulatory colleges, says the executive director of the protective association. Dr. John Gray gives credit to the colleges for more actively promoting mediated resolutions to complaints, so that patient concerns can be addressed.

But there is a growing, and troubling, trend for the regulatory colleges to require more personal information about doctors at the time of license application or renewal, he adds.

For example, the Ontario college has said it will require doctors to disclose whether they carry blood-borne pathogens such as HIV or hepatitis, he says.

The question is intrusive, but even more disquieting is what could happen to the information, given a tendency of courts and public inquiries to require colleges to disclose information they have about physicians, Gray adds. "That is very worrisome to us, so we are saying, if there isn't an absolute necessity to collect this information, why are you doing it?"

The protective association's fees are set on a regional basis - there is no cross-subsidy. Gray says that 2009 will mark the first year in which none of the regions will see a fee increase. In 2007, on an aggregate basis, member fees paid to the association decreased.

Other highlights from the association's annual report to members on Aug. 20, 2008, in Montréal, Quebec:

- The association paid \$3 million for insurance against extraordinary claims in 2006 but beginning in 2007 decided to self-insure. A "risk retention reserve fund" now totals \$3 million. 